\title{
Sobre la "presencia" del objeto de conocimiento en la teoría de la intencionalidad de Duns Escoto
}

\author{
Julio C. Vargas \\ Universidad del Valle, Colombia
}

Resumen: Esta investigación examina la teoría de la intencionalidad de Duns Escoto y se plantea la pregunta por la presencia del objeto intencional, por sus modalidades y por la manera como tiene lugar la identificación como primer paso del conocimiento. En el desarrollo del trabajo se explicitan las dos modalidades de la "presencia": de una parte, a través de las especies sensibles y de la imagen $\mathrm{y}$, de otra parte, a través de la especie inteligible. El interés es determinar en qué medida la especie inteligible sirve como medio para el brillo del objeto intencional, bajo el trasluz de las formas a priori, universales. Que el objeto intencional se corresponde en último término con la naturaleza común nos lleva a plantear la pregunta por la unidad de la esencia o naturaleza común, en cuanto antecede a la realización del acto intencional.

Palabras clave: imagen; especie inteligible; esencia; intencionalidad; identificación

\begin{abstract}
On the 'presence' of the Object of Knowledge in Duns Scotus' Theory of Intentionality". This paper deals with Duns Scotus's intentional Theory and poses the question on the presence of the intentional object, its modalities and how the identification is made, as a first level of knowledge. Throughout this paper, two forms of the presence are explained: on the one hand, through the sensible species and the image and, on the other hand, through the intelligible species. The aim is to determine up to which point the intelligible species can help to enhance the brilliance of the intentional object with the support of the a priori forms, the universals. The correspondence between the intentional object and the common nature leads to posing the question for the unity of the essence or common nature, in so far as the essence precedes the realisation of the intentional act.
\end{abstract}

Keywords: image; intelligible species; essence; intentionality; identification 
Uno de los retos centrales de toda teoria de la intencionalidad consiste en mostrar cómo tiene lugar la manifestación del objeto de conocimiento, cómo es posible que el entendimiento pueda acceder a su ser propio y -sobre esta base- establecer su unidad, sobre la cual descansa la verdad. La filosofia de Duns Escoto ofrece una concepción peculiar del aparecer del objeto en tanto resultado de la interacción de dos causas parciales: el objeto natural y el entendimiento. Desde el punto de vista noético, el conocimiento se realiza en tres fases: en primer lugar, la afección sensible del objeto da lugar a la imagen; luego, el entendimiento produce la especie inteligible, en la cual "resplandece" el objeto inteligido; finalmente, el entendimiento aprehende el ser del objeto y realiza sus respectivas inferencias. En este contexto surge la pregunta por la manera cómo tiene lugar la "manifestación" del objeto de conocimiento, cómo se entrecruzan sensibilidad y entendimiento, y en qué consiste la identificación del objeto por parte del entendimiento.

El "resplandecer" es una metáfora que designa la comprensión intelectual, la cual tiene lugar en la especie inteligible como resultado de la operación del intelecto agente e intelecto paciente. La primera fase del conocimiento es incipiente, parte de la sensibilidad y de la imagen, que sirve de base a los fenómenos adscritos al orden de lo singular, en el que aún no se puede hablar, en sentido estricto, de presencia. Con el concurso de la imagen, el entendimiento accede al orden de lo general o universal, en el cual tiene lugar la auténtica manifestación del objeto, la “especie inteligible”. Según esto, la comprensión es resultado de la aprehensión del entendimiento que instala el escenario para que tenga lugar la manifestación del objeto intencional. Sin embargo, ¿en qué consiste esta presencia del objeto al intelecto? Escoto afirma que la especie representante remite a lo representado. La indagación se dirige a establecer en qué sentido la especie inteligible "presenta" el objeto inteligido, cómo puede una presencia intelectual dar cuenta, al mismo tiempo, de la generalidad y referirse al objeto extramental, y sobre qué base es posible hablar de especies inteligibles si ellas no son vividas ni pueden conocerse directamente, sino que son el medio que remite al objeto intencional y a la naturaleza común. ¿Tiene sentido hablar de una suerte de "imagen mental"?

Las reflexiones escotistas sobre el problema del conocimiento están al servicio de la teología, de la indagación sobre cómo puede el ser humano 
conocer a Dios y en qué medida contribuye la revelación divina cristiana a la salvación y bienaventuranza humanas. Para ello, la teoría del conocimiento debe hacerse cargo de algunas temáticas centrales, tales como la delimitación de la razón humana y la descripción de las estructuras del conocimiento. En su célebre tratado titulado "Teorias de la intencionalidad en la Edad Media", Dominik Perler ofrece algunas indicaciones contextuales que ayudan a aclarar el sentido de la teoría escotista del conocimiento. Señala que, si bien Duns Escoto critica la teoría iluminista del conocimiento -expuesta por Enrique de Gante-, su principal interés es la defensa de la posibilidad del conocimiento, frente a los argumentos académicos o escépticos ${ }^{1}$. El pensamiento escotista se propone mostrar que los seres humanos están en condiciones de acceder a la verdad mediante la razón natural, sin necesidad de la iluminación divina. La razón humana puede describir los atributos esenciales de un objeto más allá de la simple constatación empírica y contingente.

Desde el punto de vista metodológico, cabe señalar que examino la teoría de la intencionalidad de Escoto al trasluz de la pregunta por el aparecer del objeto de conocimiento, sin detenerme a examinar sus antecedentes ni los vínculos que su teoría de la intencionalidad tiene con pensadores que lo antecedieron, tales como Alberto Magno y Tomás de Aquino, Enrique de Gante y Pedro de Juan Olivi. Tampoco me ocupo de la manera en que dicha teoría suscitó reacciones de aceptación o rechazo entre los siglos XIV y XVI. Estas reflexiones se restringen al conocimiento de la naturaleza material ${ }^{2}$ y buscan determinar cómo tiene lugar el aparecer referido a los objetos naturales. El propósito es establecer cómo entiende Escoto el aparecer de la realidad natural, concreta, y de qué manera es posible su conocimiento. El tratamiento del aparecer ofrece un indicio sobre cómo tiene lugar la manifestación del mundo y de sus respectivos objetos.

\footnotetext{
1 Cf. Perler, D., Theorien der Intentionalität im Mittelalter, Fráncfort d.M., Klostermann, 2004, p. 186. Las referencias a la edición crítica de Duns Escoto, Opera omnia vaticana, las realizaré indicando el nombre de la obra, seguido de la parte y el número del parágrafo, a lo que luego añado el número del volumen y de la página. Cf. Ord. I, d. 3, p. 1, n. 218-22, Vat. III, pp. 132-134.

2 Desde el punto de vista de la teoría del conocimiento, Escoto distingue tres grandes campos cognoscibles: 1) La esfera de los principios lógicos, cuyo conocimiento es evidente y a priori. Sus términos pueden ser aprehendidos por el entendimiento (por ejemplo, en la proposición el todo es mayor que la parte, el entendimiento puede acceder válidamente tanto al "todo", como a la "parte"). Tales principios fundan las inferencias lógicas y determinan la forma de los juicios. 2) La realidad natural, cuyos principios y causas son accesible a través de la experiencia (tal es el caso de la inducción). 3) La dimensión psíquica, que realiza las acciones propias del alma. Cf. Ord. I, 3, pars 1, q. 4, n. 229-240, Vat III, pp. 138ss.
} 
Para dar cuenta de la teoría de la intencionalidad de Duns Escoto es necesario establecer qué entiende por “objeto" y cómo se efectúa el respectivo acto de identificación. Los objetos cuentan con un modo de ser propio, el cual, si bien está en correlación con un acto mental que los aprehende, no impide que estos se distingan de dicho acto, pues cuentan con una unidad esencial de la cual dependen los atributos relativos o accidentales. De este tema nos ocupamos en el primer parágrafo, donde también esbozamos la diferencia entre el ente como objeto de la lógica y de la metafísica. En el segundo parágrafo, describimos la primera fase del conocimiento y el saber que le corresponde, el cual no alcanza sino a ofrecer una noción general y confusa de lo percibido. En el tercer parágrafo, presentamos los dos modos del aparecer: por una parte, la manifestación que tiene lugar en la especie sensible y en la imagen; por otra parte, la manifestación en la especie inteligible. En el último parágrafo examinamos las propiedades del objeto intencional, correlato del conocimiento. Subrayaremos, en especial, su carácter esencial, inteligido, correlato del pensamiento.

\section{Sobre el objeto del conocimiento y su identificación}

Desde el punto de vista ontológico, siguiendo a Aristóteles, Escoto diferencia dos tipos de objetos: reales y racionales. Los primeros existen en la realidad natural, cuentan con esencia y atributos, y son predicables mediante las categorias. Al igual que los entes reales, los entes racionales cuentan con un modo de ser propio, son aprehendidos mediante la acción del entendimiento y conforman los denominados "universales" que pertenecen al orden del lenguaje. De ahí que expresen la verdad, la falsedad o incluso la carencia, como es el caso de la ceguera. Con todo, Escoto reinterpreta dichos conceptos del siguiente modo: a) reelabora el concepto de ente real y acuña el concepto de ens naturae, cuyo modo de ser es primordialmente esencial, correlato del pensamiento. Los objetos naturales comparten la misma condición y son extramentales ${ }^{3}$. Ejemplos

$2223^{3}$ En el primer período de su pensamiento, cuando aún no había elaborado el concepto de "naturaleza común", Escoto los describe en los siguientes términos: "El ente es de doble manera, esto es, natural y racional. El ente de la naturaleza es, en cuanto tal, aquel cuyo ser no depende del alma. En cambio, por el ente racional se entiende aquel a cuyas nociones adviene la razón en las cosas mismas, entre ellos contamos al género, especie, definición y otros semejantes" "Similiter, logica est de ente communi, sive considerat. Sed duplex est ens, scilicet naturae et rationis. Ens autem naturae, in quantum tale, est cuius esse non dependet ab anima. Sed ens rationis dicitur de quibusdam intentionibus quas adinvenit ratio in ipsis rebus, cuiusmodi sunt genus, species, definitio et huiusmodi”. Cf. Escoto, Quaest. Super lib. Elench. q. 1, n. 2, en: Opera philosophica II, Quaestiones in Libros Perihermenias, Opus \& Opus II: Quaestiones Super Librum Elenchorum 
de ens naturae son una planta, un caballo, entre otros. b) Siguiendo a Avicena, afirma que los entes racionales (ens rationis) son resultado de la comparación entre dos o más conceptos, de manera que en ellos el pensamiento -mediante las intenciones segundas- vuelve sobre su propia actividad e identifica las formas comunes a todos los objetos (ens comunissime sumptum). Los entes racionales, en cuanto formas comunes a todo tipo de entes, son objeto de la lógica. Mediante ellos se efectúa tanto la definición como la predicación o descripción de los atributos de todo tipo de objetos, sean naturales o racionales.

El ens rationis puede significar o bien las intenciones segundas -resultado de la actividad del intelecto-, o bien el ser objetivo -la cosa en cuanto pensada o representada-. La lógica se ocupa de los objetos del pensamiento, aprehendidos por el intelecto como "intentio" o determinación pensada. La metafísica se ocupa de la quididad del ser en general, lo que hace a un ente como fijamente determinado, "ens ratum", distinto de lo meramente pensado. El ens ratum, ratificado, es aquel que rechaza de antemano la imposibilidad de su existencia y se distingue de la aliquitas, el ser meramente algo ${ }^{4}$. De este modo, metafísica y lógica cuentan con dos objetos definidos: la primera se ocupa de la quididad o esencialidad de los entes en cuanto existentes; la segunda, del ente en cuanto pensado desde el punto de vista formal ${ }^{5}$. Sin embargo, puesto que la metafísica tiene como objeto al "ente en cuanto ente", no se exime de indagar el ser de los objetos del pensamiento, es decir, racionales ${ }^{6}$.

Siguiendo a Aristóteles, Escoto afirma que el conocimiento supremo es de carácter inteligible, de mayor rango que el conocimiento perceptivo o sensorial, pues el primero accede al ser esencial de los objetos, mientras que el segundo tan solo permite constatar la presencia o existencia de algo sin añadir nada al respectivo concepto de ente ${ }^{7}$. Adicionalmente, el contenido esencial puede, en cuanto conocido, permanecer en el alma, así el objeto empírico desaparezca.

\footnotetext{
Aristotelis, and Theoremata, Andrews, R. y otros (eds.), Nueva York: The Franciscan Institute, St. Bonaventure, 2004, p. 272).

4 Cf. Ord. I, p.2, q. un., n. 302, Vat III pp. 184-185.

5 Para una investigación sobre el objeto de la lógica y de la metafísica, en el marco de la filosofia de Duns Escoto y sus antecedentes, cf. Salinas, H., "Dignitas et nobilitas metaphysicae: Objeto y articulación de la metafísica en el prólogo del comentario de Duns Escoto a la Metafísica de Aristóteles", en: Revista Española de Filosofía Medieval, 23 (2016), pp. 241-258; "La determinación de la lógica como ciencia común intencional en Duns Escoto", en: Franciscanum, v. LVIII, 165 (2016), pp. 51-86; "El universal lógico como modus concipiendi en Duns Escoto", versión en vías de publicación, facilitada por el autor, 2018.

6 Cf. Escoto, Quaest. Super lib. Elench. q. 1, n. 2, Op. Phil. II, p. 273.

7 En un pasaje del "Comentario a la Metafisica", afirma que la ciencia se ocupa primordialmente de esencias, de la quididad de su respectivo objeto: "scientia autem stricte sumpta per demons-
} 
Si bien en su grado más alto el conocimiento se entiende como explicación de las causas, su operación fundamental es la "identificación", es decir, la aprehensión del ser esencial de un objeto por parte del intelecto. Realizada en el concepto y con el concurso de una base sensible, la "identificación" se basa en la distinción, en la exclusión de otros objetos y atributos externos al objeto. Para Escoto, la función primordial del conocimiento la realiza el concepto, lugar de la verdad: la percepción es una condición necesaria para el conocimiento, una de sus causas, pero este tan solo tiene lugar en sentido pleno, "distintamente”, cuando se efectúa en concordancia con lo que expresa la definición ${ }^{8}$. El "conocimiento actual" de los objetos naturales se realiza sobre la base de la afección sensible, a partir de la cual el entendimiento genera un concepto. Sin embargo, el conocimiento perceptivo es precario, sometido a la fluctuación de lo empírico: en los primeros estratos del conocimiento reina la confusión, mas no en el sentido de una noción vaga del objeto. Cuando un objeto es percibido por primera vez, la vía para referirlo es el "nombre", que ofrece una comprensión global de la cosa, al modo de una totalidad, sin llegar a determinar las partes o atributos que la constituyen. En contraposición, el "conocimiento distinto" tiene lugar cuando el entendimiento cuenta con la definición del objeto, esto es, con su esencialidad ${ }^{9}$. Puesto que el conocimiento no se realiza en un solo paso (de la ignorancia a la verdad) en el primer nivel, el entendimiento accede directa y confusamente a la cosa percibida sin identificar su esencialidad: tan solo cuenta con su nombre. Para determinar lo percibido se requiere del concurso de conceptos que permitan superar lo confuso y acceder a la claridad del significado. La identificación es el resultado de la distinción entre el ser de lo conocido y lo semejante: el entendimiento es capaz de distinguir objetos simultáneamente presentes o de reconocer un mismo objeto en distintos momentos y circunstancias.

La identificación es progresiva y parte de la "especie especialísima", esto es, del conocimiento que se logra con base en la afección por parte de singularidades, de las cuales tan solo se puede saber que están conformadas por sustancia y accidentes sin que se pueda determinar su individualidad ni establecer un conocimiento general. Posteriormente, el entendimiento aprehende la quididad con sus respectivos atributos esenciales, compartidos por todos

trationem simpliciter abstrahit ab actuali existentia ...tum non scitur aliquid pertinens ad exsistentiam, sed consequens quidditatem". Met. VI, q. 2, n. 25, (Op. phil. IV, pp. 46).

8 Ord. I, d. 3 Vat. III, n. 72, pp. 49-50.

9 Cf. Ord I d3, n. 72, Vat. III, pp. 49-50. 
los ejemplares de la misma especie. Identificado el objeto, el entendimiento accede a un punto de partida para posteriores inferencias. A esto lo denomina Escoto "conocimiento habitual": “...cuando el objeto está presente al entendimiento como inteligible en acto de manera que el entendimiento puede realizar al instante un acto elícito acerca de aquel"10. En lo que sigue intentaremos determinar de qué manera entiende Duns el vínculo entre manifestación del objeto e identificación, así como el papel que juega allí la especie inteligible, y cómo tiene lugar la verdad.

\section{El primer grado del conocimiento, la especie especialísima y el conocimien-} to confuso

El primer grado de conocimiento lo constituye la "especie especialísima", esto es, el conocimiento simple que se forma a partir de una singuralidad percibida, la cual, si bien aún no está determinada, puede ser entendida a partir de una noción. Tal es el caso de quien ve una persona a cierta distancia sin poder identificarla suficientemente: de ella puede decir que es un individuo, un humano. La simple noción de "humano" no permite determinar de qué persona se trata. La especie especialísima es resultado de una acción del entendimiento que intenta comprender en qué consiste el singular percibido en determinado momento. En este primer nivel, el entendimiento tan solo accede a una definición, a un saber que no se corresponde con la quididad de lo visto: una unidad demasiado amplia, la cual aún no permite identificar los atributos esenciales. Como quien dice "veo algo alli al fondo de la vía, puede ser un animal o un ser humano"11.

Desde el punto de vista lógico, la especie expresa aquello a lo que apunta la definición, es decir, su contenido, aplicable a varios individuos. Se denomina especialísima aquella especie que no admite ser dividida en subespecies, sino que conforma la especie menor y predicable de varios individuos. En relación al conocimiento de lo singular, Escoto afirma que la especie especialísima es el "concepto perfectísimo", el mejor posible, que corresponde a la primera fase del conocimiento. Ella tan solo permite conocer confusamente al singular,

${ }^{10}$ Ord I d. 3 n. 92, Vat III, p. 60, trad. Ordín G. y Guzmán M.

11 "Propondré, en primer lugar, cuál es el orden en que se originan en el conocimiento actual los conceptos que entendemos confusamente; y, en cuanto esto, digo que lo primero que conocemos actual y confundentemente es la especie especialísima, cuyo singular mueve primero más eficazmente y más fuertemente nuestro sentido, y esto, en el supuesto de que esté presente al sentido en la debida proporción" (Ord. I d3 n. 73, Vat. III, pp. 50, traducción de Juan Ortín García y Guzmán Manzano). 
entenderlo a partir del "nombre"12, de la palabra que da cuenta de lo singular, sin lograr acceder a su naturaleza específica, a su quididad: "La causa natural produce su efecto con todo el poder de que es capaz, cuando no está impedida. Por tanto, produce primero el efecto más perfecto que puede producir primero. Todos los concurrentes a este acto primero del entendimiento son causas meramente naturales, ya que son anteriores a todo acto de la voluntad y no están impedidas, como es patente; luego primero producen el concepto más perfecto que pueden: este no es otro que el concepto de la especie especialísima producida"13.

Siguiendo a Avicena, Escoto afirma que las nociones que corresponden a la "especie especialísima" no forman parte de los principios que condicionan el conocimiento, propios de la metafísica, pues ellos son punto de llegada del conocimiento. De lo contrario, ni la percepción ni el conocimiento científico se podrian desarrollar sin antes disponer de un saber explícito de la metafisica ${ }^{14}$.

A esta primera fase del conocimiento, en la cual el entendimiento cuenta con un concepto como punto de apoyo, sigue un proceso de "descomposición" (resolutio) cuyo resultado es el acceso al ser esencial del objeto, efectuado por los distintos tipos de ciencias. El último grado de esta "descomposición" lo realiza la ontología, pues accede a los principios del "ente en cuanto ente". La primera fase del conocimiento ofrece una primera aproximación, confusa, con respecto al ser del objeto. En ella, aún no se puede hablar en sentido estricto del aparecer que conduce al conocimiento, pero sí de un aparecer que remite a la singularidad. En lo que sigue nos ocupamos de las modalidades del aparecer y de las especies sensibles e inteligibles, en donde tiene lugar la manifestación del objeto.

3. Sobre el doble aparecer del objeto de conocimiento: la manifestación basada en la especie sensible y en la imagen, y la manifestación basada en la especie inteligible

El presupuesto básico de la teoría escotista de la intencionalidad es que 226 el objeto cuenta con una autonomía tal que no es constituido por el entendimiento, sino que ejerce una afección sobre el alma, al modo de causa parcial del conocimiento. Entendimiento y objeto fungen como dos variables interde-

12 Ord. I, d. 3, p. 1, n. 72, Vat. III, p. 50.

${ }^{13}$ Cf. Ord. I d. 3, n. 76, Vat. III, p. 52, traduccón de Juan Ortín García y Guzmán Manzano.

${ }^{14}$ Cf. Ord I d3 n. 77, Vat. III, p. 53. 
pendientes que producen el conocimiento. El entendimiento es esencialmente inmaterial, de manera que su dependencia de los sentidos, en esta vida, es accidental: es un límite impuesto por la caída. En nuestra condición actual, el intelecto no puede acceder a los individuos, sino al aspecto universal y común que puede estar presente en ellos de una manera virtual o real. El entendimiento cuenta con preeminencia respecto de la afección sensible, producida por el objeto natural, y realiza una "trasposición" 15 , esto es, un proceso que parte de la manifestación sensible (en la imagen o en las especies sensibles) y concluye con la manifestación espiritual del objeto a través de la especie inteligible, en la que aparece el objeto al modo de una "representación", relativo al acto (secundum quid). El contenido de la especie, de carácter general o universal, remite al objeto intencional o absoluto. Por ahora interesa dejar sentado que, en el primer nivel del conocimiento, la percepción presupone la existencia de la unidad sustancial y objetiva que corresponde al objeto singular.

Puesto que en el primer nivel del conocimiento el entendimiento tan solo accede a una noción indeterminada del objeto, es necesario precisar cómo tiene lugar la aprehensión de la respectiva "quididad", gracias a la cual se pueden describir los atributos esenciales y accidentales, y cómo tiene lugar esta modalidad de la "presencia" o "manifestación" del objeto. Para ello, debemos precisar qué entiende Duns por "presencia". Como es de esperarse en una teoría filosófica que presupone la capacidad del conocimiento para acceder a la verdad, el conocimiento tiene como fundamento la presencia del objeto, al cual debe corresponder una unidad propia y objetiva ${ }^{16}$. Esta puede ser de dos modos, acordes con las funciones disímiles pero complementarias de la sensibilidad y el intelecto: a) la presencia fenoménica, que se efectúa a través de las especies sensibles y la imagen; b) la presencia fulgurante, que tiene lugar gracias a la acción del entendimiento.

La primera modalidad de la presencia tiene lugar en las especies sensibles y en la imagen. Las primeras son la representación formal del objeto, se asemejan a él y surgen en el alma a partir de la afección del objeto presente, aquí y ahora. La imagen es la representación de un objeto que ha sido previamente percibido: el "fantasma conoce al mismo (objeto) presente en conformidad con una especie y esta especie puede ser especie del objeto, así este no exista ni esté presente, por eso el conocimiento del fantasma es abstractivo en relación con

${ }^{15} C f$. Boulnois, O., Etre et representation, París: Épimété, 1999, p. 84ss.

${ }^{16}$ Cf. Ord. I, n. 368, Vat III, p. 224. 
el sentido particular"17. Desde el punto de vista noético, la imagen o fantasma es resultado de la unificación de las afecciones sensibles por parte de la imaginación, "la causa el alma en sí misma "con maravillosa rapidez"18. Ella misma no aparece, sino que sirve de medio para la presentación del objeto. Desde esta perspectiva, la imagen es "ratio cognoscend"19. Es condición del conocimiento y representa la singularidad. Con todo, en este nivel no se puede hablar de "identificación" o de una aprehensión simple: así la imagen represente lo singular, este no aparece con una identidad propia, distinto de otro singular, ya que es un rendimiento del entendimiento. La imagen ofrece la representación sensible de un objeto que funge como portador de atributos comunes y universales, con las respectivas condiciones individuales, tales como cualidad, cantidad, figura y tiempo. No obstante, estos solo pueden explicitarse mediante la acción del entendimiento, el cual hace uso de los universales para separarlos e integrarlos en un todo complejo ${ }^{20}$.

En la sensibilidad y en la imaginación (facultades inferiores) se hace presente el objeto, mediante ellas es posible acceder a sus aspectos característicos, tales como el matiz de color, el olor, el tamaño, entre otros. En este nivel tiene lugar la primera relación intencional con el objeto, en la cual este es aprehendido al modo de atributos que forman parte de una singularidad. Estos conforman una modalidad efectiva de aparición, aunque no alcanzan el grado de la universalidad y, por tanto, en ellos no se realiza efectivamente el conocimiento $^{21}$. Para que tenga lugar el conocimiento, el objeto debe ofrecerse a la luz de los conceptos, de lo universal o general. La "presencia" que sirve de condición para la acción del intelecto se efectúa en dos tipos de actos intencionales: "afirmo que, en relación con los objetos que no están presentes en sí, es decir, aquellos que conocemos de un modo natural, el acto del intelecto es doble: el primer acto es la especie por la cual el objeto está presente en calidad

${ }^{17}$ Cf. Ord. II, 3, 323, Vat. VII, p. 554: "Sensus enim particularis, est obiecti secundum quod est per se et in se exsistens, - phantasia cognoscit idem secundum quod est praesens per speciem, quae especies posset esse eius licet non esset exsistens vel praesens, ita quod cognitio phantastica est abstractiva respectu sensu particularis...".

18 Cf. Ord. I, d 3, n. 506, Vat. III, p. 300.

19 Cf. Ord. II, d. 3, n. 340, Vat. VII p. 564; Boulnois, O., Etre et representation p. 80; Pérez, A., "Entendimiento agente y abstracción en Duns Escoto", en: Revista Española de Filosofía Medieval, 9 (2002), pp. 125-145, p. 19.

${ }^{20}$ Cf. Ord. I, 3, q.1, n. 365, Vat. III, p. 221 ss.

21 "Otras capacidades cognitivas [distintas a las del intelecto] tienen presente al objeto y no de un modo segundario ...sino en su propia presencialidad: por ejemplo, el color está presente en el sentido común, no solo en cuanto está presente a la visión, sino porque el órgano del sentido común contiene una especie de color" (Ord. I, n. 367 Vat. III, p. 223). 
de objeto inteligible en el acto... Para realizar el primer acto (de la producción de especies), el entendimiento agente actúa en relación con el fantasma, y alli el intelecto agente es causa más primordial que el fantasma y los dos conforman en conjunto una causa total en relación con la especie inteligible ${ }^{22}$.

El primer acto intencional -denominado por Pini ${ }^{23}$ "abstracción"24_ consiste en la identificación o aprehensión del objeto, resultado de la interacción entre el fantasma y el entendimiento. Sin embargo, el entendimiento no actúa directamente sobre el fantasma, ya que entre ellos no se efectúa una sintesis de manera que se produzca una unidad objetiva de otro nivel. El entendimiento abstrae los atributos singulares de un objeto, parte de la imagen y accede a los atributos esenciales, de manera que produce una especie inteligible en la cual no solo hay una comprensión del objeto, sino que este se presenta de manera efectiva, reluce en cuanto inteligido, independiente de la presencia material propia de la imagen y de la especie sensible. Escoto no afirma que entre la imagen -o fantasma- e intelecto haya una sintesis. La actividad del intelecto es engendrar o producir la especie inteligible.

En cuanto medio de exposición del objeto, la especie inteligible conforma el objeto primero que le corresponde al intelecto. En relación a ella tiene lugar propiamente la "identificación" del objeto y de los aspectos comunes, universales, presentes o relucientes en la imagen. Surge la pregunta sobre cómo tiene lugar este aparecer eminente del objeto que hace posible el conocimiento. Escoto afirma que la especie es engendrada por el entendimiento, el cual actualiza lo ya sabido al modo de una "forma real" o "forma representante" que se hace cargo del objeto en cuanto universal, sobre cuya base el intelecto puede volver sobre sus propios actos, establecer relaciones. Hemos visto que el entendimiento efectúa una "transposición" de órdenes: sobre la base de la imagen sensible accede a una imagen espiritual del objeto. Con ello sucede un tránsito de lo "no universal a lo universal". Lo universal se hace presente en la especie inteligible, la cual es un contenido mental que funge como "forma" universal, predicado que da cuenta de los aspectos comunes, generales, pero

\footnotetext{
${ }^{22}$ Cf. Ord. I, d. 3 n. 563, Vat. III p. 335: "dico quod dúplex est actus intellectus respectu obiectorum quae non sunt prasentia in se, qualia sunt illa quae modo naturaliter intelligimus: primus actus est species, qua obiectum est praesens ut obiectum actu intelligibile (...) Ad primum autem actum agit intellectus agens cum phantasmate, et ibi intellectus agens est principalior causa quam phantasma, et ambo integrant unam totalem causam respectu speciei intelligilis",

${ }^{23}$ Cf. Pini, G., "Two Models of Thinking: Thomas Aquinas and John Duns Scotus", en: Klima, G, ed., Intentionality, Cognition, and Mental Representation in Medieval Nueva York: Fordham University Press, 2014, p. 15.

${ }^{24}$ Cf., ibid., p. 15.
} 
que aún no constituye la representación del objeto intencional. La universalidad es solo la "condición del objeto en cuanto objeto"25. Dado el carácter restringido de la manifestación sensible -la cual remite a la singularidad- para que haya conocimiento se requiere de una presencia de otro tipo, no material, sino espiritual: el entendimiento produce su propio objeto de conocimiento, el cual se manifiesta desde el punto de vista universal o general, esto es, de un modo amplio y simple, sin alcanzar aún al objeto intencional, propiamente dicho. En palabras de Escoto: "el objeto (inteligible) precede naturalmente al acto de intelección; de ahí que la universalidad, condición propia del objeto en cuanto objeto, precede al acto del intelecto, es decir, al acto de conocimiento. Luego, es necesario que el objeto esté presente al intelecto bajo la razón de la universalidad, porque la presencia del objeto precede al acto"26.

Según esto, el entendimiento forja la especie inteligible y, con ella, la "presencia" del objeto. Desde el punto de vista de la especie inteligible, el objeto "reluce" en tanto que (forma) universal. De ahí que la especie inteligible sea tema de la lógica, la "luz" desde la cual el entendimiento agente aprehende el ser de los objetos. Con todo, la especie inteligible no es el objeto en cuanto tal, "absoluto", sino la forma real, que corresponde al aparecer. En cuanto "razón formal del conocimiento"27, la especie inteligible por sí misma no representa nada, sino que es un medio de presentación. Conformada por un saber general, universal, propicia la remisión al objeto inteligido; pero, de modo semejante a la imagen sensible, ella misma no aparece, sino que funge como condición del conocimiento del objeto. Es una "imagen espiritual"28.

En cuanto contenido mental representante del objeto, la especie inteligible produce una afección o alteración en el intelecto. Desde este punto de vista, es "una determinación accidental del intelecto"29. La especie inteligible forma parte del acto intelectivo, funge como el "sentido", el cual es asignado por cada persona que comprende al objeto desde un punto de vista determinado. Desde este punto de vista, la especie inteligible es un "cuasi instrumento" o un

${ }^{25}$ Cf. Ord. I, d. 3, n. 350 Vat III, pp. 210. Cf. ibid, n. 360, p. 218ss.

${ }^{26}$ Cf. Ord. I d3 n. 350, Vat III pp. 210-211: "obiectum est prius naturaliter actu: ergo universalitas, quae est propia conditio obiecti in quantum obiectum, praecedit actum intellectus vel intelligendi; ergo sub illa ratione etiam oportet obiectum esse praesens, quia praesentia obiecti praecedit actum".

${ }^{27}$ Cf. Ord I, d3 n. 382 Vat III p. 232.

${ }^{28}$ Cf. Honnefelder, 2005, p. 33; Boulnois 1999, p. 88.

${ }^{29}$ Cf. Escoto, D., In Perihermeneias I, q. 2, n. 20ss, n. 39: Op Phil. II, pp. 51, 56; Honnefelder, L., Duns Scotus, MÚNICH: Beck, 2005, p. 38. 
"mecanismo intelectual" 30 , que coactúa con el entendimiento en la producción del conocimiento. En ella tiene lugar un reconocimiento del objeto con base en el universal sin que se haya efectuado aún el conocimiento en sentido estricto. En este sentido antecedente, el conocimiento funge al modo de la memoria, la cual no tiene nada ver con la capacidad de conservar imágenes, representaciones y palabras ${ }^{31}$. El conocimiento se realiza efectivamente a partir de la actividad del intelecto, en el segundo acto intencional, que se dirige activamente hacia el objeto una vez que el intelecto pasivo ha sido afectado por la especie inteligible: “...el intelecto no solo sufre realmente una afección del objeto real, que imprime una especie real, sino también [sufre una segunda] afección intencional, en la medida en que el objeto brilla en la especie. Y esta segunda afección es la 'recepción del conocimiento' -en la medida en que esta parte de lo cognoscible en cuanto cognoscible, brilla en la especie inteligible-y este 'sufrir' es el 'conocer"'32.

La primera intención corresponde a la impresión de la especie inteligible en el entendimiento pasivo. Con ello, a partir de la especie inteligible o "razón formal absoluta", se produce la aprehensión simple o identificación del objeto intelectual, es decir, el primer modo de la presencia. Con todo, en este primer nivel no tiene lugar el conocimiento, pues la especie inteligible forma parte del acto intencional. Es el a priori que funge en el acto intencional para iluminar o permitir la presencia del objeto intencional ${ }^{33}$.

Que el conocimiento sea intencional significa que la actividad del intelecto es mucho más que una simple afección: es una "acción absoluta" de parte del "alma". Que el conocimiento sea una "acción absoluta" significa que es una acción perfecta, esto es, su fin último no es externo a la realización del acto ${ }^{34}$.

${ }^{30}$ Cf. Perler, D., Theorien der Intentionalität im Mittelalter, Frankfurt a. M.: Klostermann, 2004, p. 208; Ord I d 3, n. 562, Vat III pp. 334.

31 "Para que el intelecto tenga el carácter de memoria, es necesario poner una especie inteligible en el intelecto, que represente lo universal como universal, y que sea anterior por naturaleza al acto de conocer, por estas razones ya expuestas en relación al objeto, en cuanto universal y en cuanto presente ante el intelecto. Estas dos condiciones, esto es, de universalidad y de presencia, preceden naturalmente la intelección". "...necesse est ponere in intellectu ut habet rationem memoriae, speciem intelligibilem reprasentantem universale ut universale, priorem naturaliter actu intelligendi, - propter istas rationes iam positas ex parte obiecti, in quantum universale et in quantum praesens intellectui: quae duae condiciones, scilicet universalitas et preasentia, preacedunt naturaliter intellectionem" (cf. Ord. I, dist. III, p. 3, qu. 1, n. 370, Vat. III, p. 225).

${ }^{32}$ Cf. Ord. I, d. 3 n. 386, Vat III, p. 235: "intellectus non tantum patitur realiter ab obiecto reali, imprimente talem especiem realem, sed etiam ab illo obiecto ut relucet in specie patitur passione intentionali: et illa secunda passio est 'receptio intellectionis' - quae est ab intelligibili in quantum intelligibile, relucens in specie intelligibili - et illus 'pati' est 'intelligere"'.

${ }^{33}$ Cf. Boulnois, O., Etre et representation, p. 87.

34 "Al parecer el intelecto solo padecerá de parte de lo inteligible en cuanto inteligible, sino solo en cuanto sufre una afección real, por recibir alguna forma que es como la perfección real del inte- 
La acción intencional segunda es un movimiento intencional hacia el objeto sobre la base de su presencia efectiva. A esto lo denomina Escoto "intelección actual" o "habitual"35. En ella, el intelecto ejerce su acción sobre la especie intelectiva, de forma tal que dirige su atención al objeto inteligido y establece relaciones e inferencias: "El segundo [acto] es la misma intelección actual, y el entendimiento actúa en relación con cada uno de estos actos, sin ser movido por la causa parcial concurrente en vistas a aquella acción, aunque sea legítimo que un único acto del intelecto (la intelección) esté precedido por su movimiento hacia otro acto (la producción de la especie inteligible). ...Para realizar el segundo acto, actúan tanto la parte intelectiva [ya sea como intelecto agente, ya sea como intelecto posible, no me ocupo de esto por ahora] como la especie inteligible como dos causas parciales, y aquí actúa la parte intelectiva sin ser movida por la especie, sino movilizando en primer lugar; es decir, que actuando en alguna medida es como la especie coopera con aquella (parte intelectiva)" 36 .

En este nivel, la atención se dirige al objeto en cuanto inteligido, de manera que puede determinar sus atributos ontológicos, es decir, su naturaleza común. El contenido del acto intencional es el objeto en cuanto tal, su ser absoluto que se hace presente a la mirada intencional.

En definitiva, el aparecer del objeto tiene dos modalidades que se corresponden con las funciones de la especie inteligible: en primer lugar -y con antelación al conocimiento efectivo-, ejerce una relación de "semejanza" con el objeto. $\mathrm{El}$ intelecto produce una forma universal, dispone de un saber de un objeto y piensa en términos de conceptos reales (por ejemplo, de un objeto percibido en cuanto casa colonial) con cierto tipo de estructura. En este nivel todavia no tiene lugar el conocimiento, sino la consideración formal y conceptual del objeto. De lo dicho se desprende que le corresponde a la lógica considerar el acto intencional y la especie inteligible, en la cual surge el sentido del objeto.

lecto. En efecto, recibe esa especie como un sujeto recibe un accidente real. Por eso, el intelecto no padece de parte de lo inteligible en cuanto inteligible. De donde se sigue también que el 'conocer' (intelligere) no será un movimiento de la cosa hacia el alma. Más bien toda la intelección será una acción absoluta suya, como una forma que está en sí, sin tener ningún término afuera" (cf. Ord. I, d. 3, n, 336 Vat III, p. 203).

${ }^{35}$ Cf. Ord. I, d.3 n. 92 Vat III, p. 60.

${ }^{36}$ Cf. Ord. I, d. 3 n. 563, Vat. III p. 335: “...secundus actus est ipsa intellectio actualis, - et ad utrumque actum agit intellectus, non motus ab eo quod est causa partialis secum concurrens ad illam actionem, licet unum actum intellectus praecedat motio eius ad alium actum. (...) Ad secundum actum agit pars intellectiva (sive intellectus agens sive possibilis, non curo modo) et species intelligibilis sicut duae partiales causae, - et ibi agit pars intellectiva non mota a specie, sed prius movens, id est quasi agens ut species sibi coagat". 


\section{El objeto inteligido como correlato del acto intencional}

Desde el punto de vista ontológico, la especie inteligible es una forma a priori, de la cual dispone el entendimiento para aprehender el ser esencial de cualquier objeto, desde el punto de vista de su significado, dicho sea, del concepto. Si mediante un acto reflexivo la metafísica y la teoría del conocimiento consideran su modo de ser, no se podría requerir de otra especie inteligible adicional que las haga presentes, puesto que son "cualidades absolutas" que no logran el estatuto ontológico de un objeto natural o inteligido. Por eso, la afirmación nominal "especies" es aproximativa, pues ellas mismas no aparecen, sino que están al servicio del aparecer en el acto intencional: "La especie inteligible es una cualidad absoluta. Esto, al menos, es necesario que lo concedan los que afirman que la especie es la razón formal de entender, es decir, que es per se la que comienza el acto (de conocer). Y, a pesar de ello, comúnmente se la llama "semejanza del objeto", no porque ella sea la relación que lleva consigo per se la palabra 'semejanza', sino porque ella por su naturaleza es una forma que imita y representa al objeto. Por eso se dice que es semejanza por imitación. Y, además, cuando es expresada por la palabra 'especie', todavía no es expresada como una entidad absoluta precisamente, sino incluyendo la relación bajo la que es entendida comúnmente" 37 .

El conocimiento se lleva a cabo mediante un acto intencional que atiende al contenido de la especie, es decir, al objeto representado en ella, lo que se manifiesta efectivamente. Desde el punto de vista noemático, el objeto se presenta como inteligido, "en un cierto aspecto" (esse secundum quid). Para referirse a él, Escoto utiliza la expresión "disminuido", lo cual no significa que el objeto quede reducido a una parte de él, ni que pierda tamaño o calidad ${ }^{38}$. Que el objeto inteligido sea "disminuido" no equivale a una modalización del ser representado o absoluto, sino a su aprehensión desde el intelecto. El objeto conocido, "disminuido", representante, corresponde al objeto representado, intencional, absoluto (esse simpliciter). En palabras de Escoto: "pues, el ser absoluto de un hombre -no el objeto disminuido- es objeto del pensamiento, pero este 'ser absoluto' en cuanto objeto del pensamiento, es ser 'desde un punto de vista determinado' (secundum quid), y por eso de ahí no se sigue: 'Homero es objeto

\footnotetext{
37 Cf. Quodl. XIII, n. 97, traducción de Ortín García y Guzmán Manzano, p. 347

38 "Lo universal como objeto, en su razón de universal, no tiene sino un ser disminuido, en cuanto ser conocido (así como Hércules en la estatua no tiene sino un ser disminuido, en cuanto está representado en la imagen). Pero si se tiene algún ser real, lo tiene en cuanto existe en algo en lo que se representa bajo esa razón" ( $c f$. Escoto, D. Reportatio I A 3 q. 4. Ed. King, 7.1ss).
} 
del pensamiento, luego Homero existe', pues esto es la falacia de confundir el 'desde un punto de vista' (secundum quid) y el 'absolutamente' (simpliciter)"39.

Escoto tiene claro que hay una gran diferencia entre el modo de ser de un objeto en cuanto conocido y en cuanto es en sí mismo, absolutamente. El objeto en cuanto tal (absoluto) se conoce siempre desde una perspectiva o punto de vista (secundum quid). La determinación secundum quid corresponde al concepto en cuanto inteligido, en él tiene lugar la representación del objeto representado, absoluto. Una cosa es Homero como objeto del pensamiento y otra Homero concebido desde un punto de vista absoluto, es decir, no supeditado a ninguna condición.

De este modo, desde el punto de vista noético, el acto intencional cuenta con a) la especie inteligible o forma universal y b) el objeto inteligido que aparece en la especie. Desde el punto de vista noemático, la referencia se hace al objeto absoluto. Por ejemplo, en la expresión "hombre muerto", la representación del término hombre es en cuanto que "muerto". De ahí que no anula al término "hombre", sino que determina un tercero, de quien se dice que ha muerto, un hombre en particular o un "objeto absoluto". Por eso, decir: "un hombre, en sentido absoluto, está muerto" es un contrasentido, porque el predicado contradice al sujeto, que se concibe como vivo. En cambio es válido decir: "un hombre desde un punto de vista particular está muerto", pues aquí la determinación se refiere a un individuo.

Aristóteles ilustra esta misma tesis con otro ejemplo: si a un etíope de tez negra se le denomina "blanco", haciendo referencia a la blancura de sus dientes, el objeto del pensamiento es la "blancura"40. Pero no se piensa la blancura en sentido absoluto, sino desde un punto de vista particular, "disminuida", en relación a los dientes de un hombre.

Con esta diferencia Escoto busca mostrar que el intelecto, sea el de Dios o el humano, puede pensar un objeto real y determinar sus atributos sin necesidad de que este exista. De este modo, aun desde el punto de vista de un intelecto eterno que conoce un objeto (por ejemplo, una rosa) el conocimiento se centra en su ser inteligido, en su ser esencial, que funge como fundamento in re. Lo cual significa que el aparecer de la rosa tiene lugar en el intelecto, en cuanto conocida, desde su posibilidad, pero no requiere de ningún soporte empírico.

\footnotetext{
${ }^{39}$ Cf. Ord. Id. 36 q. un. n. 34, Vat. VI, p. 284 : "esse enim hominis simpliciter - et non deminutum - est obiectum opinionis, sed istud 'esse simpliciter' ut in opinione, est esse 'secundum quid'; et ideo non sequitur 'Homer est in opinione, ergo Homerus est', nec etiam 'Homerus est exsistens in opinione, ergo Homerus est exsistens', - sed est fallacia secundum quid simpliciter".

40 Cf., Aristóteles, De interpretatione II, 2, 21a21-23.

ARETÉ Revista de Filosofia, v. XXXII, 1, 2020 / ISSN 1016-913X
} 
De este modo, la posibilidad asegura el ser del objeto, independientemente de sus condiciones empíricas, de su existencia o no existencia.

"Por tanto", afirma Duns, "que una cosa no tiene en la eternidad un verdadero ser de esencia o de existencia, sino que ella funda la relación ideal según un ser disminuido (deminutum) que ella posee desde la eternidad (que el verdadero ser es distinto del ser esencial y del ser de la existencia, lo expresa el libro VI de la Metafísica): si se supone que yo fuera y que conociera una rosa por la eternidad, y la conociera según su ser esencial y de existencia, entonces la conocería según su ser de esencia y de existencia, y ella no tendría sino un ser conocido -y esto aun cuando se supone que no hubiera ninguna rosa, y que, no obstante, la conozco según su ser de esencia y de existencia, aunque ella no tenga ninguno de estos seres. De acuerdo con esto, el acto del conocimiento es el ser de la esencia o el ser de la existencia. Sin embargo, aquello que se contrapone al intelecto (como objeto de conocimiento) tiene solamente un ser disminuido en el intelecto" ${ }^{41}$.

El objeto primario del conocimiento no se corresponde con el ser percibido, sino con el ser en cuanto es objeto del intelecto, tal y como es aprehendido eternamente por el ser de Dios, esto es, como ser esencial y, a la vez, como ser existente. El objeto primario del conocimiento es el objeto del pensamiento, del intelecto divino y del humano. El fundamento del conocimiento se remonta a Dios, a la manera como piensa las criaturas en su ser esencial y existente. El contenido de esta relación es que él piensa las creaturas, los entes, como posibles o como devenidos a la existencia.

En definitiva, el conocimiento se efectúa primordialmente a partir de la operación del entendimiento, el cual, con base en la afección de la especie inteligible, dirige su atención al objeto inteligido y desde allí considera el ser objetivo, ya sea en su esencia, ya sea en su existencia. Antes que determinar si el objeto existe o no existe, lo decisivo es su manifestación al modo de una realidad objetiva cuyo ser no depende de quien lo piensa o conoce: "Pues si algo

\footnotetext{
${ }^{41}$ Cf. Lect. I d. 36 q. un. n. 26, Vat XVII, pp. 468-469: "Ideo dico quod res ab aeterno non habuit esse verum essentiae vel exsistentiae, sed fundat relationem idealem secundum esse deminutum, quod habuit ab aeterno (quod est esse verum, distinctum contra esse essentiae et esse exsistentiae, sicut patet ex VI Metaphysicae): sicut si ponatur quod ego fuissem ab aeterno et quod ab aeterno intellexissem rosam, ab aeterno tunc intellexi rosam secundum esse suum essentiae et secundum esse existentiae; et tamen non habuit esse nisi cognitum, - sicut si modo rosa omnino nihil esset, intelligo rosam et secundum esse essentiae et exsistentiae, et tamen neutrum habet. Unde terminus intellectionis est esse essentiae vel esse exsistentiae, - et tamen illud quod obicitur intellectui, tantum habet esse deminutum in intellectu". Véase también Ord. I, d. 35, q. un. n. 32, Vat. VI, p. 258
} 
no existe, puede ser entendido (y esto como su esencia o como su existencia), $\mathrm{y}$, sin embargo, no es puesto por nuestra intelección lo que tiene verdadero ser de esencia o de existencia; ni hay diferencia alguna-como parece- entre el intelecto divino y el nuestro, a este respecto; salvo que el entendimiento divino produce aquellos inteligibles en su ser inteligible, y nuestro entendimiento no los produce anteriormente. Pero, si este ser no es tal que requiera ser absoluto (esse simpliciter), entonces 'producirlo en tal ser' no es producirlo en algún ser absoluto" 42 .

\section{Algunas preguntas sobre el 'aparecer'}

Hemos recorrido los diversos sentidos que asigna Duns Escoto a la presencia del objeto y su importancia para la realización del conocimiento. La primera modalidad de la presencia tiene lugar mediante la sensibilidad (especies sensibles e imagen) que representa al singular al modo de la semejanza. Sin embargo, allí no se efectúa el conocimiento propiamente dicho. La segunda modalidad corresponde a la presencia que tiene lugar en la especie inteligible, la cual es el accidente que le acaece al entendimiento, de manera tal que este forja un saber teórico y conceptual relativo al objeto. Con todo, allí tampoco se puede hablar de conocimiento en sentido estricto. La tercera modalidad de la presencia corresponde a la dación efectiva del objeto en la especie inteligible, en su relucir. En ella, el objeto aparece en cuanto inteligido o disminuido, correlato del objeto en sí o absoluto. El objeto conocido conforma el contenido del acto intencional, pero solo desde un cierto sentido o aspecto, disminuido. En relación a la presencia objetiva, lo decisivo es que ella es posible gracias a una doble condición: por una parte, depende de la representación que forja el intelecto, cuyo carácter es universal, conceptual; por otra, el objeto tiene un carácter propio, objetivo y esencial. En relación con el problema de la "manifestación" se puede establecer que la unidad objetiva, aprehendida por el entendimiento, no depende de la forma racional del intelecto, de sus conceptos universales $-a$ priori-, antes bien, el objeto cuenta con una unidad propia (objetiva), esencial, compartida por varios entes naturales. Si nos atenemos a la pregunta por el

\footnotetext{
42 Cf. Ordinatio I, d. 36, q. u., n. 28, Vat. VI, pp. 281-282: "Quia si aliquid non sit, potest a nobis intelligi (et hoc sive essentia eius sive exsistentia eius), et tamen non propter intellectionem nostram ponitur quod illud habeat verum esse essentiae vel exsistentiae; nec est differentia aliqua - ut videtur - inter intellectum divinum et nostrum, quoad hoc, nisi quod intellectus divinus producit illa intelligibilia in esse intelligibili, noster non producit primo. Sed si istud esse non est ex se tale quod requirit esse simpliciter, producere illud in tali esse' non est producere in aliquio esse simpliciter".
} 
ser del objeto natural, como por ejemplo la "rosa", ella cuenta con una identidad propia y esencial de la cual tan solo se tiene noticia mientras que se hace presente al intelecto que la piensa y la aprehende, ya sea humano o divino. En definitiva, la teoría de la intencionalidad de Escoto entiende la presencia o manifestación del objeto a partir de la correlación entre el objeto representado en el intelecto, en cuanto universal y el ser esencial, natural del objeto, cuya unidad por ser esencial no se puede asignar exclusivamente a un individuo, sino que ella es anterior a la aprehensión del intelecto. Es compartida por varios singulares, es esencial y común ${ }^{43}$. De lo anterior surgen algunas preguntas.

En primer lugar, cómo se puede entender la unidad ontológica de la naturaleza común, en cuanto correlato del acto intencional, ya que dicha unidad no viene proporcionada por el acto intencional, esto es, no es constituida ni construida por el intelecto. Que la unidad del objeto natural antecede a la ejecución del acto significa que es postulada, de manera que el conocimiento consiste en la aprehensión intencional, realizada por el intelecto, que accede a una esencia que puede corresponder a un individuo o a una sustancia segunda, un objeto universal. En todo caso, la unidad objetiva no es producida, constituida o construida por el entendimiento, sino al modo de representación. La postulación de la unidad esencial del objeto natural (ya sea de la singularidad, ya sea del objeto natural, común) permite establecer un fuerte contraste con la teoría fenomenológica de la intencionalidad. De manera que, en el pensamiento de Duns Escoto, no sería posible hablar de una "fenomenología de la verdad"44, pues uno de los distintivos de la fenomenología es dar cuenta de la constitución de la unidad objetiva a partir de la síntesis de la actividad intencional y temporal.

En segundo lugar, en relación con el "aparecer" del objeto intencional, la teoría escotista presupone que no existe una mediación entre el objeto conocido y la mente: del objeto tan solo se tiene noticia en cuanto que "disminuido". En este contexto, el aparecer del objeto intencionado tiene lugar mediante las lentes de la especie inteligible, que aseguran la captación del objeto a partir de su a priori racional, esto es, de las formas universales del conocimiento. No obstante, se impone la pregunta sobre cómo es posible conocer lo singular por ejemplo, de una persona en su ser propio-, si el saber que se tiene de ella siempre está mediado por las formas universales. Que Escoto tiene presente este

\footnotetext{
${ }^{43}$ Cf. Salinas, H., "El universal lógico como modus concipiendi en Duns Escoto", versión en vías de publicación, facilitada por el autor, 2018, p. 21ss.

44 Cf. Guerrero Troncoso, H., "Duns Escoto y la noción de verdad concebida como fenómeno", en: Revista Philosophica, 47-48 (2015), pp. 89-90.
} 
problema, lo confirma el siguiente pasaje de sus "Comentarios a la Metafisica de Aristóteles": "De otra suerte, al saber algo acerca de los universales no sabríamos nada acerca de las cosas, sino solo acerca de nuestros conceptos, y tampoco cambiaría nuestra opinión de verdadero a falso en virtud del cambio en la existencia de la cosa. Por tanto, el universal puede, estar en la cosa debido a que son la misma naturaleza aquella que está determinada en la existencia por un grado de singularidad; y la que en el entendimiento (o sea, del modo en que se halla en relación con este como lo conocido respecto del cognoscente) está indeterminada. Y así, como estas dos cosas concurren por accidente en la misma naturaleza y pueden existir una sin la otra, así también pueden estarlo la determinación y la indeterminación antedichas. A partir de esto se hace manifiesto que no es necesario que aquello que es universal esté en la cosa (aunque pueda estarlo) como sí le es necesario estar en el entendimiento"45.

Según este pasaje, una misma naturaleza está presente tanto en lo singular como en lo universal. Sin embargo, surge la pregunta de cómo es posible acceder a la singularidad, en su esencialidad, si de ella tan solo tenemos noticia por vía del entendimiento pues, a partir de la imagen, tan solo se puede acceder a un conocimiento confuso y nocional de lo singular. Con todo, esto será tema de otra investigación.

Recibido: $10 / 11 / 2018$

Aceptado: 08/10/2019

\section{Bibliografia}

Boulnois, O., Etre et representation, París: Épimété, 1999.

Elias, G., "La especie inteligible en Duns Escoto", en: Cuadernos de Filosofia, 65 (2015), pp. 5-14.

Escoto, J.D., Opera omnia III: Ordinatio I, d. 3, C. Balić y otros (eds.), Typis Polyglottis, Civitas Vaticana (Vat. III), 1954.

${ }^{45}$ Cf. Escoto, D., Quaestiones subtilissimae super libros Metaphysicorum Aristotelis. VII, q. 18, n. 59, en: B. Ioannis Duns Scoti Opera Philosophica, v. IV, Nueva York: The Franciscan Institute Publications, 1997, pp. 354-355: "aliter sciendo aliqua de universalibus, nihil sciremus de rebus sed tantum de conceptibus nostris, nec mutaretur opinio nostra a vero in falsum propter mutationem in exsistentia rei. Potest igitur universale esse in re, ita quod eadem natura est, quae in exsistencia per gradum singularitatis est determinata, et in intellectu -hoc est ut habet relationem ad intellectum tamquam cognitum ad cognoscens- est indeterminata". La indicación de este pasaje se la debo al profesor Vitor Bragança de la Universidad de Goiana-Brasil, en una conversación sostenida el 13 de septiembre de 2017 . 
Escoto, J.D., Opera omnia, Ordinatio I, d. 26-48, C. Balić y otros (eds.), Civitas Vaticana: Typis Polyglottis (Vat. VI), 1963.

Escoto, J. D.: Reportatio I A 3, q. 4., ed. King (http://individual.utoronto.ca/pking/ editions and translations.html).

Escoto, J. D., Quaestiones Quodlibetales XIII, Madrid: BAC, 1968.

Escoto, J.D., "Quaestiones super libros Metaphysicorum Aristotelis", en: B. Ioannis Duns Scoti Opera Philosophica, v. IV, Nueva York: The Franciscan Institute Publications, 1997.

Escoto, J. D., Opera philosophica II, Quaestiones in Libros Perihermenias, Opus \& Opus II: Quaestiones Super Librum Elenchorum Aristotelis, and Theoremata, Nueva York: The Franciscan Institute, 2004.

Escoto, J. D., “Cuestiones Cuodlibetales: cuestiones XIII y XIV. Ordinatio I, d. 3 p. 1 qq. 1-2; p. 3, qq. 2-3", en: Manzano Guzmán, I., Estudios sobre el conocimiento en Juan Duns Escoto, Murcia: Instituto Teológico Franciscano, 2000, pp. 291-420.

Guerrero H., "Duns Escoto y la noción de verdad concebida como fenómeno", en: Revista Philosophica, 47-48 (2014), pp. 59-89.

Honnefelder, L., Duns Scotus, Múnich: Beck, 2005.

Pérez, A., "Entendimiento agente y abstracción en Duns Escoto", en: Revista Española de Filosofia Medieval, 9 (2002), pp. 125-145. https://doi.org/10.21071/refime. v9i.9343

Perler, D., "What Are Intentional Objects? A Controversy among Early Scotists", en: Perler, D. (ed.) Ancient and Medieval Theories of Intentionality, Leiden: Brill, 2001, pp. 203-226.

Perler, D., Theorien der Intentionalität im Mittelalter, Fráncfort d.M.: Klostermann, 2004. https://doi.org/10.3196/9783465032892

Pini, G., "Two Models of Thinking: Thomas Aquinas and John Duns Scotus", en: Gyula, K. (ed.), Intentionality, Cognition, and Mental Representation in Medieval Philosophy, Nueva York: Fordham University Press, 2015. https://doi.org/10.5422/ fordham/9780823262748.003.0004

(http:/ / faculty.fordham.edu/pini/pini/Blank_files/Two\%20Models\%20of\%20Thinking. pdf)

Salinas, H., "Dignitas et nobilitas metaphysicae: Objeto y articulación de la metafísica en el prólogo del comentario de Duns Escoto a la Metafisica de Aristóteles", en: Revista Española de Filosofia Medieval, 23 (2016), pp. 241-258. https://doi. org/10.21071/refime.v23i.8981

Salinas, H., "La determinación de la lógica como ciencia común intencional en Duns Escoto”, en: Franciscanum, v. LVIII, 165 (2016), pp. 51-86. https://doi. org/10.21500/01201468.2183

Salinas, H., "El universal lógico como modus concipiendi en Duns Escoto", versión en vías de publicación, 2018. 